Wisley F. Sales

wisley@pucminas.br

Pontifical Catholic University of Minas Gerais - PUC Minas

30535-901 Belo Horizonte, MG. Brazil

\author{
Álisson R. Machado \\ Senior Member, ABCM \\ alissonm@mecanica.ufu.br \\ Federal University of Uberlândia - UFU \\ School of Mechanical Engineering \\ 38408-100 Uberlândia, MG. Brazil
}

John Bonney

bonnyj@|sbu.ac.uk

Emmanuel O. Ezugwu

ezugwueo@lsbu.ac.uk

London South Bank University - LSBU

Engineering, Science and The Built Environment SE1 OAA London, United Kingdom

\section{Evaluation of Cutting Fluids Using Scratch Tests and Turning Process}

This work demonstrates that scratch test techniques can be used to provide a quick and cost effective evaluation of cutting fluids. Apparent coefficient of friction and specific energy for the scratch steel samples under several lubrication conditions provides a good indicator of cutting fluid performance. This is followed by evaluation of the surface finish and the cutting force of the ABNT NB 8640 steel with emulsion and synthetic cutting fluids, at $5 \%$ of concentrations, and neat mineral oil in the turning process. Comparative tests were carried out under dry and wet conditions. Results show that the linear scratch test was not efficient while the pendular scratch test was efficient tool in the classification of cutting fluids. The results can be transferred to conventional machining due to its dynamic nature.

Keywords: scratch tests, cutting fluid, cooling, lubricity, turning

\section{Introduction}

The use of cutting fluids during machining was pioneered by Taylor who in 1883 showed that cutting speed could be increased by up to $40 \%$ by using water as a coolant (Taylor, 1907). Nevertheless, water does not efficiently "wet" metal, since it has a low wetting ability (lubrication) at higher temperature conditions when it looses its cooling efficiency and lubrication capacity (Ferraresi, 1977). Also water causes ferrous metals to corrode. This problem is solved by addition of mineral and vegetable oils to water as cutting fluids Such mixtures, containing up to $30 \%$ of vegetable oils is a better lubricant than water hence significant reduction in friction between the tool and the workpiece can be achieved during machining. Neat oils of any type have poorer cooling capacity than emulsions or aqueous solutions. Oils, due to their high lubricity, reduce friction considerably at the cutting interface. In an attempt to combine both the cooling and lubrication characteristics of cutting fluids, aqueous cutting fluids classified as emulsions, and solutions were developed. Such mixtures exhibit better wet ability and cause less oxidation than pure water and furthermore have higher lubricating power.

Nowadays, cutting fluids have better cooling and lubricating properties as well as longer lifetime. There is no "universal cutting fluid" which is ideal for all machining processes, hence new formulations are frequently developed and tested for specific cooling situations. The pressures from health and environment protection agencies mean that cutting fluids need to be less damaging to the environment and free from sulphides and chlorides. Good cutting fluids not only have better cooling and lubrication properties but can also be easily disposed after treatment, converting it into environmental friendly product.

Selection of lubricant for machining depends on factors such as costs and its effect on the environment as well as health of the

Paper accepted March, 2007. Technical Editor: Anselmo Eduardo Diniz machine tool operator. The use of minimal quantity lubrication during machining is justified, as the chip-tool contact area, where material shearing/deformation and rupture occur, is very small. This means small quantity of lubricant (typically $5-20 \mathrm{ml} / \mathrm{h}$ ) will be needed. Low dose lubricant application during machining has been shown to improve tool life (Machado, 1997).

Cutting tools materials for both dry and wet machining are continually being improved to maintain superior properties like toughness, hot hardness, low sensitivity to thermal shocks and chemical wear attack.

The wide variety of commercially available cutting fluids today means that the choice of appropriate cutting fluids for machining processes are made without considering factors intrinsic to each situation. Evaluating the behaviour of cutting fluids during machining operations require a lot of time effort and the associated high costs (Cselle, 1997, Chiffre, 1978, 1981, 1984, 1988; Wakabayashi, 1989).

This study proposes alternative methodologies for evaluating and quantifying the major characteristics of cutting fluids, i.e. cooling and lubrication. Two techniques are frequently used to study the behaviour of abrasive wear system employed for evaluation of the fluid characteristics. These are linear and pendular scratch tests (Lamy, 1984; Liang et al, 1996; Raslan, 1991), performed in laboratories and not involved directly with machining. Cutting force and roughness of the machined surface were used as indicators of the performance of the cutting fluids.

\section{Experimental Procedures}

Six different machining environments evaluated in this study are water, dry, neat oil, two synthetic oils and one emulsion. A short description of the cooling and/or lubrication characteristics of these fluids are given bellow:

- Water: Has an excellent cooling ability, but is a poor lubricant; 
- Dry: Minor cooling ability and no direct lubricity (a thin oxide layer with low shear strength could grow between the surfaces to improve lubrication, but it depends on materials involved);

- Neat oil: Good lubricity and anti-corrosion properties, but has low thermal conductivity (low specific heat) hence poor cooling ability;

- Emulsion: Have high specific heat, with a good thermal conductivity, but its lubrication ability is considerably poor. The additives in its formulation, based on sodium, reduces the superficial stress of steam bubbles formed at high cutting temperatures, and hence rendering the ability of the bubbles to easily break and improve cooling;

- Synthetic: Have high specific heat and excellent thermal conductivity. Most of synthetic fluids contain poliglycol supplemented by additives (extreme pressure, biocides, detergents, etc).

All the trials using water based fluids like emulsion and synthetic were conducted at $5 \%$ concentration.

The study was divided into two parts. The first part involves using both linear and pendular scratch test techniques to evaluate the environments while the second stage involved machining (turning) trials. Results from both parts analysed and possible correlations between them were evaluated.

\section{Step I - Laboratory Tests}

\section{Linear Scratch Test}

The linear scratch test used in this work was designed, built and evaluated by Abrahão et al (1998). Figure 1 shows, schematically, a pair of indenters and samples. Before the test, the indenter is allowed to touch the surface of the sample at the beginning and end of the specified scratch length in order to draw a reference line. The depth of scratch is measured in relation to this line. A computer program was written that allows the correction of possible difference in levels between the supporting and scratching surfaces. If the test is carried out at constant depth of cut the displacement of the indenter is along a line parallel to the reference line. Tests were conducted at constant load and at the following conditions: dry, neat oil, water, emulsion and multi purpose grease.

The sample is a transverse section $5 \mathrm{~mm}$ thick cut using a mechanical saw, from ABNT NB 8640 steel bar of $102 \mathrm{~mm}$ diameter cross section. The samples were further cut into blocks of 40 X 25 X $5 \mathrm{~mm}$ with $\mathrm{SiC}$ abrasive disc using a cooling fluid. The faces of the sample were ground and lapped with $\mathrm{SiC}$ abrasives, 80 and 600 Mesh respectively. Finally, the faces were polished with diamond paste to a $3 \mu \mathrm{m}$ finish.

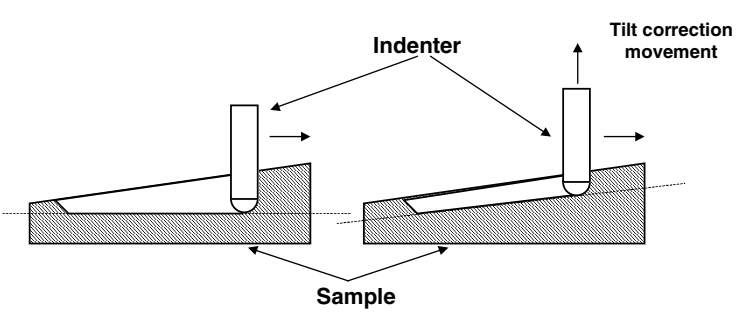

Figure 1. Movement of the indenter.

The scratch tests were performed with a Vickers diamond indenter with square base pyramid, with an attack angle of $22^{\circ}$. The scratch speed of the indenter is $500 \mu \mathrm{m} / \mathrm{s}$, normal load of $5 \mathrm{~N}$ and scratch length of $10 \mathrm{~mm}$ were kept constant. The sample was rigidly held in a specially made cylindrical container, such that the surface to be scratched was immersed in a layer of $6.8 \mathrm{~mm}$ fluid as illustrated schematically in Figure 2.

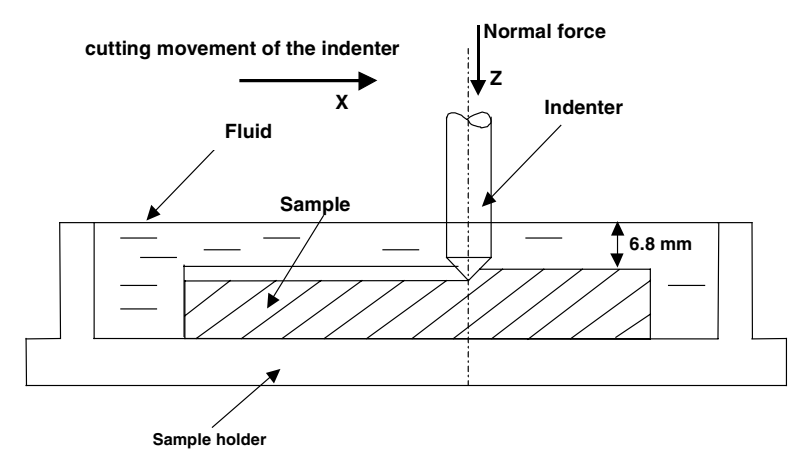

Figure 2. Cutting fluid immerged sample.

The system automatically maintains the normal load at the adjusted value and the scratch depth can be varied during the test. At any instance during the scratching process the tangential force is measured and recorded. This is used to determine the apparent friction coefficient, $f$, defined by Equation 1 . The $10 \mathrm{~mm}$ length scratches were produced at an acquisition rate of $300 \mathrm{~Hz}$.

$$
f=\frac{F_{t}}{F_{n}}
$$

Where $F_{t}$ is the tangential force and $F_{n}$ the normal force.

\section{Pendular Scratch Test}

The test consists of producing a scratch in a sample with an indenter of a defined geometry (Lamy, 1994; Liang et al, 1996). Pendulum used has a mass of $2.860 \mathrm{~kg}$, set free at a $154^{\circ}$ angle, with $19 \mathrm{~J}$ energy and a percussion speed of $4.1 \mathrm{~m} / \mathrm{s}$. The indenter is fixed at the extremity of the pendulum, with previously adjusted mass. It is let go from a defined height (initial potential energy) to scratch the sample located at the rest position of the pendulum in oil. After the scratch, the pendulum rises to a certain height, which is recorded on a scale. The scale registers directly the energy consumed in the test, i.e. the difference between the initial and final potential energy of the pendulum. The sample surface is submerged in a layer of cutting fluid. The sample is weighed before and after the scratch. The specific energy is calculated, which is the ratio between the energy used to scratch the sample and the loss in mass. The pendular scratch test used in this work was designed, built and evaluated by Franco (1989). Figure 3 is a schematic drawing of the pendular instrument used.

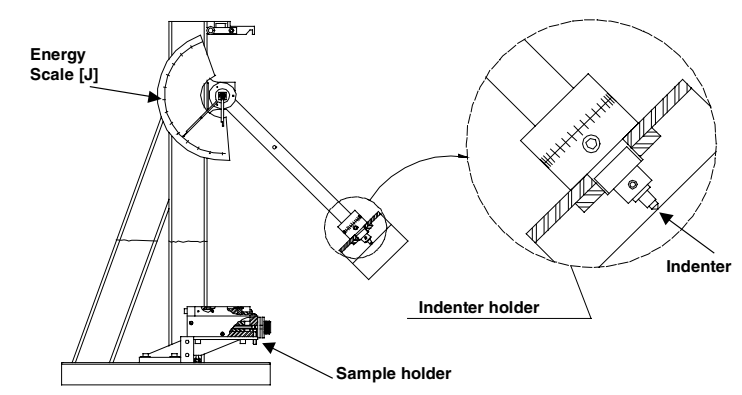

Figure 3. General view of the pendular instrument (Franco, 1989). 
According to Franco (1989), the percussion speed of $4.1 \mathrm{~m} / \mathrm{s}$ (246 $\mathrm{m} / \mathrm{min}$ ) is comparable to cutting speeds employed during machining process, hence the temperatures generated during the scratch test are expected to be high.

The samples for this test were similarly prepared as for the scratch test but with the dimensions of $11 \times 11 \times 60 \mathrm{~mm}$. From a $5 \mathrm{~mm}$ side square bar obtained by powder metallurgy (WC and Co) process, a square base pyramid indenter was cut out. The faces were ground and polished to $3 \mu \mathrm{m}$ finish. In order to prevent fragmentation of the indenter tip it was truncated by $0.48 \mathrm{~mm}$ square sides measured using an image analysing system. Figure 4 is a schematic drawing of the indenter tip.

After each scratch test is conducted, the indenter faces were observed with a magnifying glass at 25 times magnification. If any adhered material or small wear of the indenter tip is observed, the indenter is reconditioned by polishing before the next test.

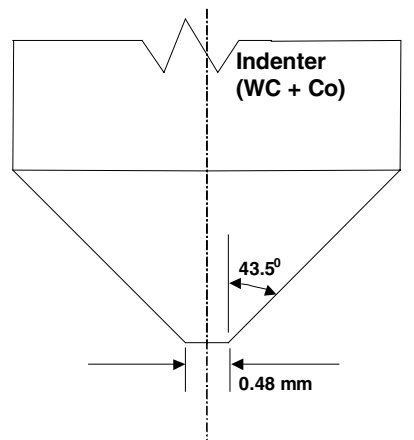

Figure 4. Details of the indenter tip.

The surface of the sample to be scratched is submerged completely within the cutting fluid to be analysed to a depth of 3 $\mathrm{mm}$. This is achieved by using a tape to create a suitable wall to contain the fluid. Figure 5 is a schematic illustration of the sample with the face submerged in the cutting fluid.

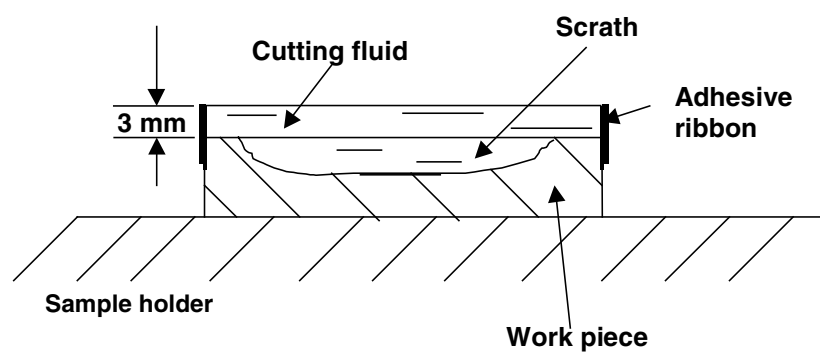

Figure 5. Surface of the sample submerged in the cutting fluid.

In this test configuration the dept of the scratch is variable and the maximum value is adjustable using a screw with filler gauge, which elevates or lowers the table with the sample, from 40 to 250 $\mu \mathrm{m}$. The sample was weighed before and after the test and then submerged in acetone and washed in an ultra-sound cleaning machine for 5 minutes. It was then dried in a jet of hot air. Trials were conduced with the following fluid conditions: dry, neat oil, water, emulsion, synthetic 1 and synthetic 2 .

\section{Micro Hardness Analysis of Chip Samples}

Chip samples were collected for analysis after scratching in the following medium: dry, neat oil, emulsion and synthetic 1. Using a
Carl Zeiss micro durometer the Vickers micro hardness was measured with a load of 50 gf. The hardness is measured at three randomly selected points on the thicker and thinner sections of the chip. The average hardness value represents the hardness of the chip.

\section{Step II - Machining Trials}

The performances of the fluids were evaluated in a turning process. In order to classify the performance of the cutting fluids by monitoring the cutting force and the surface finish generated during the machining process. This will determine the performance of the cutting fluids, in terms of lubricity and cooling ability. Cutting speeds $\left(\mathrm{v}_{\mathrm{c}}\right)$ of $8.6 ; 27.7 ; 86.2 ; 172.4 ; 218.6$ and $277 \mathrm{~m} / \mathrm{min}$ and a constant feed rate (f) of $0.138 \mathrm{~mm} / \mathrm{rev}$ and the depth of cut (doc) of $1 \mathrm{~mm}$ were employed. The fluid conditions used were dry, emulsion, synthetic 1 and net oil. The cutting fluid was applied through an overhead position at a flow rate to $3.5 \mathrm{l} / \mathrm{min}$.

Workpiece material was AISI 8640 steel bar of $98 \mathrm{~mm}$ diameter and $500 \mathrm{~mm}$ long with an average Vickers hardness of $290 \mathrm{HV}$. The cutting tools used were TiN coated cemented carbide, with ISO specification P35, designated SQNR 120408. The mounted tool in the tool-holder has the following cutting geometry: $\alpha_{0}=5^{\circ} ; \beta_{0}=$ $79^{\circ} ; \gamma_{0}=6^{\circ} ; \chi_{\mathrm{r}}=75^{\circ} ; \varepsilon_{\mathrm{r}}=90^{\circ}$ and $\lambda_{\mathrm{s}}=0^{\circ}$.

The cutting force $\left(\mathrm{F}_{\mathrm{c}}\right)$ was measured using a dynamometer. At each cutting condition the surface is machined to a length of $10 \mathrm{~mm}$. Computer, data acquisition board and software (manufactured by Kistler) were used to acquire the data at an acquisition rate of 100 $\mathrm{Hz}$. The surface roughness parameters, $\mathrm{R}_{\mathrm{a}}$ and $\mathrm{R}_{\max }$, were measured using a profilometer with a cut off length of $0.8 \mathrm{~mm}$. The surface roughness value is measured at 3 different spots and the average value is taken as the surface roughness value.

\section{Results and Discussions}

\section{Linear Scratch Test}

The objective of the linear scratch test is to identify the accessibility of the fluid to the indenter-chip interface in an attempt to better define the frictional coefficients existing at the fluid conditions investigated: dry, water, emulsion at 5\% concentration, neat mineral oil and a multi purpose grease (with extreme pressure additives). Figure 6 shows plots of the apparent friction coefficient for the various media investigated.

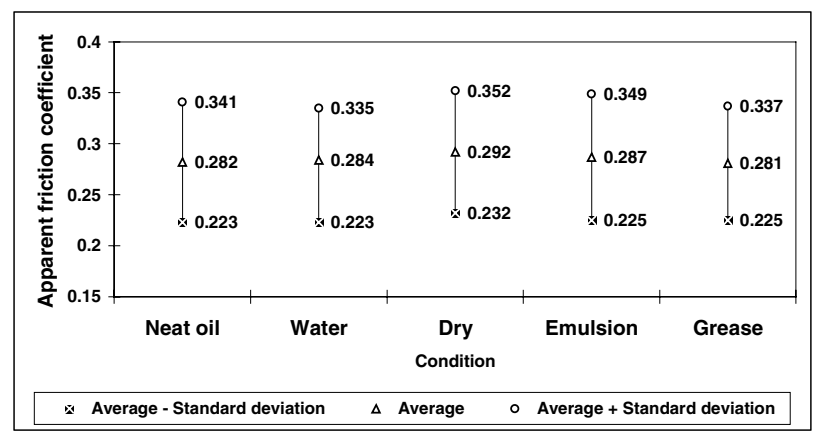

Figure 6. Average friction coefficient - scratch performed with a constant load of $5 \mathrm{~N}$, scratch speed of $0.5 \mathrm{~mm} / \mathrm{s}$ and sample acquisition rate of 300 Hz.

It can be seen that there is minimum variation in the apparent friction coefficient (f), for all the conditions investigated. The least average friction coefficient was recorded for grease, followed in 
ascending order by neat mineral oil, water, emulsion and dry. However a true statement cannot be made on the relative lubricity of the various fluids evaluated due to measurement variability.

\section{Pendular Scratch}

Figure 7 shows the variation of specific energy consumed during the sample scratching with the sample mass loss. Figure 8 shows plots of the curves fitted with a power model suggested by Franco (1989). Figures 7 and 8 shows that the specific energy of scratching increases steeply with decreasing mass loss (scratch depth) lower than $2 \mathrm{mg}$, independent of the lubrication condition used. This was linked to size effect (Backer, 1952) and the mechanisms of chip formation (Bryggman, Hogmark and Vingsbo, 1985).

The relation between the specific energy and loss in mass is expressed as follow:

$$
e=K \cdot V^{q}
$$

where $\mathrm{K}$ and $\mathrm{q}$ are coefficients dependent on the material and $\mathrm{V}$ is the average volumetric variation (volume of material loss) in the test.

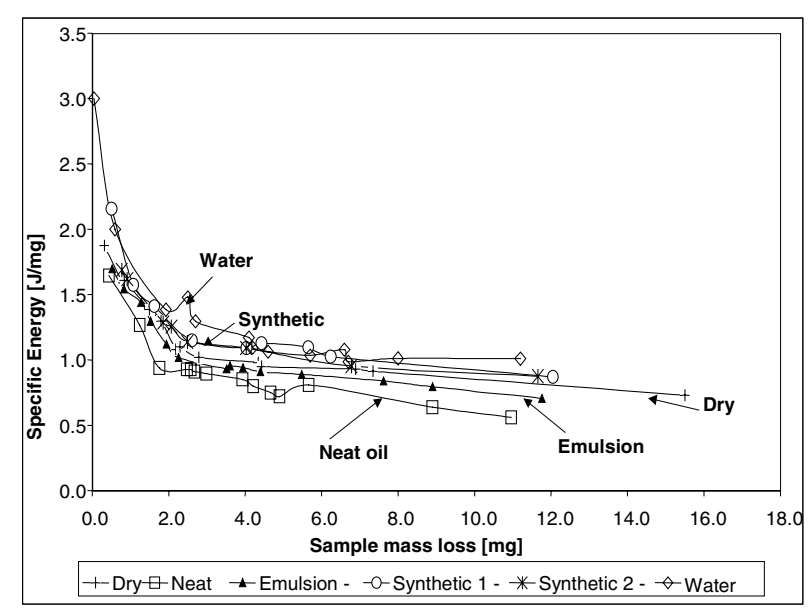

Figure 7. Specific energy consumed in ABNT NB 8640 steel test samples immerged in cutting fluid - experimental points.

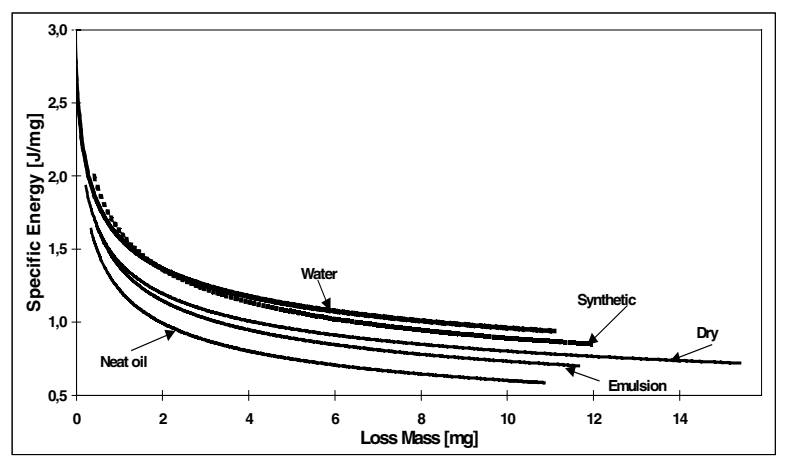

Figure 8. Curves adjusted through a power model.

Table 1 shows the coefficients $\mathrm{K}$ and $\mathrm{q}$ from Equation 2, calculated using mass loss $(\Delta \mathrm{m})$ instead of the volumetric variation $(V)$, different environments and the correlation coefficient " $R$ " between adjusted and actual curves.
Table 1. Parameters of the power model adjustment.

\begin{tabular}{|c|c|c|c|}
\hline Fluid & $\mathbf{K}$ & $\mathbf{q}$ & $\mathbf{R}$ \\
\hline Water & 1.6132 & -0.2242 & 0.9802 \\
\hline Neat oil & 1.2592 & -0.3192 & 0.9787 \\
\hline Emulsion & 1.417 & -0.285 & 0.9820 \\
\hline Dry & 1.444 & -0.254 & 0.9871 \\
\hline Synthetic & 1.6667 & -0.2699 & 0.9790 \\
\hline
\end{tabular}

Equation (2) can be modified by replacing $\mathrm{V}$ with $\Delta \mathrm{m}$ as it is proportional to the volume. Thus Eq. (2) can be written as:

$$
e=K \cdot \Delta m^{q}
$$

There is a high correlation between the raw and fitted curves. The calculated correlation coefficient of 0.97 and above was achieved for all the fluid conditions investigated. Thus the best relation between the specific energy and mass of material loss is an exponential one as expressed in Eq. (3). The fluids performances in terms of increasing specific energy are: neat oil, emulsion, dry, synthetic and water.

The pendular scratch approaches the surface of the work sample at a speed of $246 \mathrm{~m} / \mathrm{min}$ (Franco, 1989). This is a cutting speed practical for machining steel with cemented carbide tools. The depths of scratch can be varied up to $300 \mu \mathrm{m}(0.3 \mathrm{~mm})$, which is comparable to the depth of cut used in machining. Also the temperatures generated at the scratch interface are high, as verified by the blue colour of the chip when scratched in dry condition.

The fluids with higher heat exchange capacity (water 209.3 and synthetic $328.9 \mathrm{~W} / \mathrm{m}^{2} . \mathrm{K}$ (Sales et al, 2002)) generated higher specific energy (see Fig. 7 and 8 ). Those with higher lubricity ability have a lower specific energy. During the scratching process, a considerable part of the energy is converted to thermal energy. The scratch takes place at an extremely restricted area that suggests a sudden increase in temperature, thus softening the sample material and making shearing easier. Since the synthetic fluid has excellent heat exchange (cooling) and low lubricating properties, the scratch always happens at lower temperature. This minimises the softening of the work sample and with inefficient lubrication higher specific energy value is recorded. On the other hand, neat oil has a poor heat exchange capability, but has an excellent lubrication property. This results in decreased friction coefficient at higher temperatures, making it easier to cut (scratch) the metal with lower energy consumption.

The heat generated when scratching under dry condition is mainly conducted into the sample material and also by convection into the surrounding air. However, the heat exchange here is relatively low, compared to exchange in water or synthetic fluids. On the other hand, the poor lubrication property of the surrounding air puts the dry scratch condition in an intermediate position among the fluids investigated as illustrated in Figures 7 and 8 . The emulsion fluid has an intermediate lubricating and cooling properties. Hence the effect of softening and friction reduction at the scratch indenter/sample interface is also intermediate. This justifies the fact that medium energy is consumed during the scratching process, lower than in dry condition but higher than when scratching in neat oil.

Figure 9 shows micrographs of the scratch produced under dry condition: (a) is a view looking at the scratch bottom (top view) while (b) is a view looking at the scratch walls (side view). 


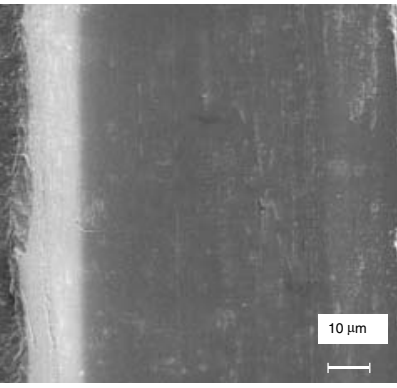

a) Upper view

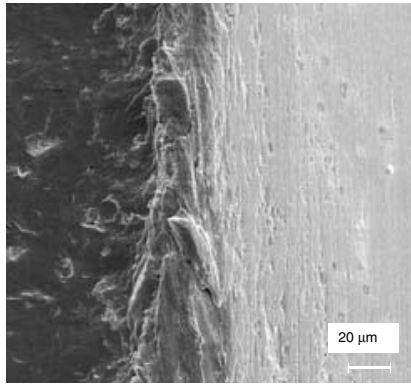

b) Side view
Figure 9. Scratch produced in the dry condition.

Figure 10 and 11 show micrographs of scratches produced in the neat oil and synthetic fluid respectively.

Micrographs of the side views of the scratches show that mild scratch was produced with neat oil and more severe scratch under dry condition. With synthetic fluid the degree of severity is at intermediate level. It can also be observed in Figures 9 to 11 that intense plastic deformation occurred at the side walls of the scratch The dominant mechanism is the micro cut and a small quantity of micro ploughing.

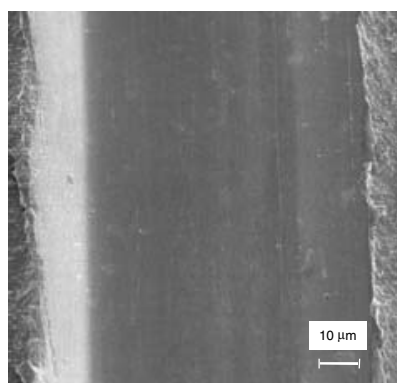

a) Upper view

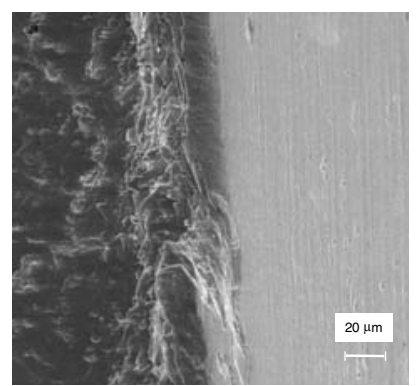

b) Side view
Figure 10. Scratch produced with the neat oil fluid.

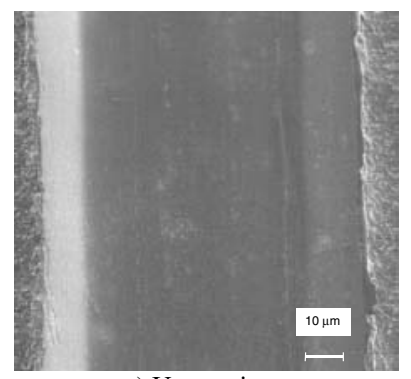

a) Upper view

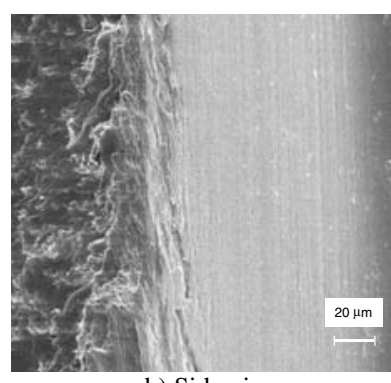

b) Side view
Figure 11. scratch produced with the synthetic fluid.

Figure 12 shows plots of the average micro hardness values of the chips produced in the various fluids during the pendular scratch tests.

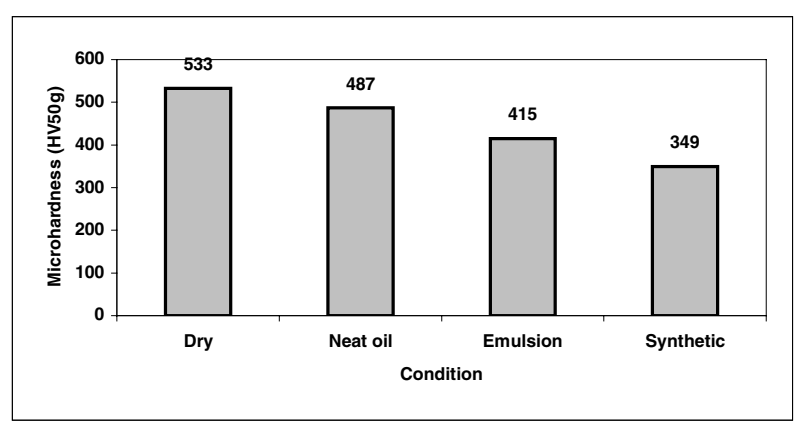

Figure 12. Average Vickers micro hardness of the chip section (load of 50 g).

The hardness of the chip increased in the following order of fluid used: synthetic, emulsion, neat oil and dry. According to ElKhabeery, Salch and Ramadan (1991), high cutting speed increase plastic flow rate and consequently the temperature at the chip-tool interface. This extends the plastic flow beneath the machined surface. The higher plastic flow rate (high dislocation density), together with higher temperatures contribute to increased hardening and consequently the micro hardness levels. Submerged sample surfaces within the coolant experience high heat exchange and consequently lower temperatures. This leads to lower deformation of both chip and work piece and the hardness of the chip.

In the dry condition, natural convection is not enough to promote cooling. Therefore, high temperatures and plastic flow occur, consequently the micro hardness is greater than in other conditions. The neat oil fluid has a poor heat exchange, as reported by Sales et al (2002). Nevertheless, the heat exchange are slightly greater than in dry condition, thus the chip hardness levels are lower than in the dry condition, but higher than in the other fluids investigated. The synthetic fluid is an excellent coolant, hence the scratch is produced at lower temperatures and deformations consequently the hardness of the chip is the lowest ( $349 \mathrm{HV}$ ). Visual observation of the colour of the chip suggest that the temperatures at the indenter-sample interface were in descending order of dry condition, neat oil, emulsion and synthetic.

\section{Cutting Force and Surface Finish in Turning Operation}

Figure 13 shows cutting forces recorded at various speeds and cutting fluids conditions.

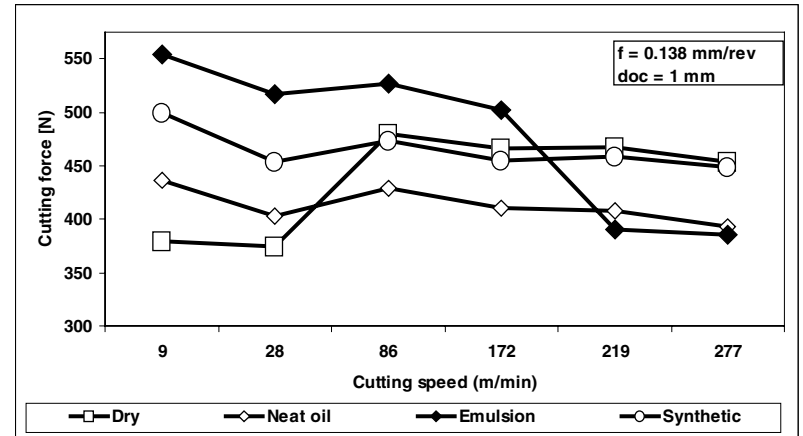

Figure 13. Variation of the cutting force with cutting speed for the several fluids.

It can be seen that lower forces was generated at very low cutting speeds (up to $28 \mathrm{~m} / \mathrm{min}$ ) when the presence of built up edge (BUE) is eminent when machining dry. Under these conditions, the 
BUE may alter the geometry of the tool rake face. This makes the rake angle positively inclined, hence lowering the cutting forces. Increase in the cutting speed generally increases temperature at the chip-tool interface (Trent, 1991). The emulsion fluid has additives, which has the ability to reduce steam bubble formation (which acts as a barrier preventing access to the cutting interface by fresh fluid). It can be observed that the emulsion generated the lowest cutting force at cutting speeds in excess of $172 \mathrm{~m} / \mathrm{min}$. The neat oil, which has a good lubricating properties, when machining at all cutting speed investigated, generated low cutting forces. The use of neat oil is, however, hindered at higher speed conditions because of the high risk of ignition.

Figures 14 and 15 are plots of the variation of surface roughness values, $R_{a}$ and $R_{\max }$, respectively at various cutting speeds and cutting fluids. The figures clearly show that improved surface finish were produced when machining with cutting fluids, while the worst surface finish was recorded under dry conditions.

It is also evident from Figures 14 and 15 that at lower cutting speeds, independent of the lubrication condition applied, the presence of BUE worsens the surface finish. Machining at higher speed conditions elevates the temperature at the cutting interface (Trent, 1991; Sales et al, 2002) and reduces cutting forces and vibrations, resulting in the generation of better surface finish. Temperatures generated at the chip-tool interface during turning process can be up to $1000{ }^{\circ} \mathrm{C}$ depending on the cutting conditions employed (Trent, 1991). The dominant material removal mechanisms during the machining process, under all cutting conditions investigated are the micro cut with small amount of micro ploughing. The results of a laboratory test can be used in real situations as far as they reproduce similar actuating mechanisms.

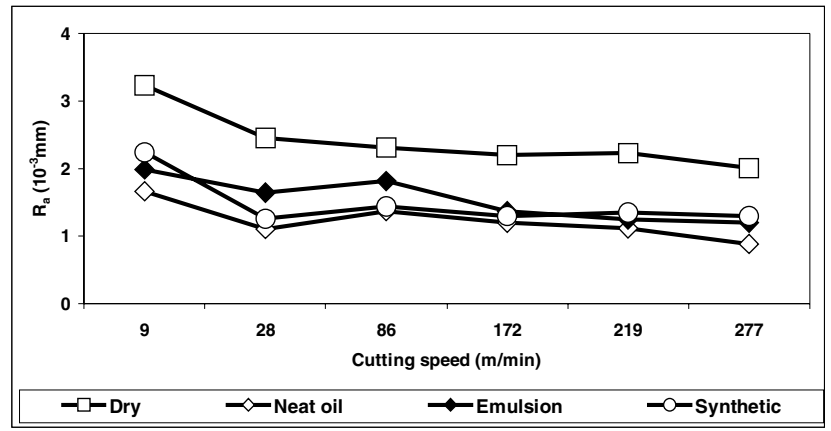

Figure 14. Average surface finish (Ra) generate at various cutting speeds and cutting fluids.

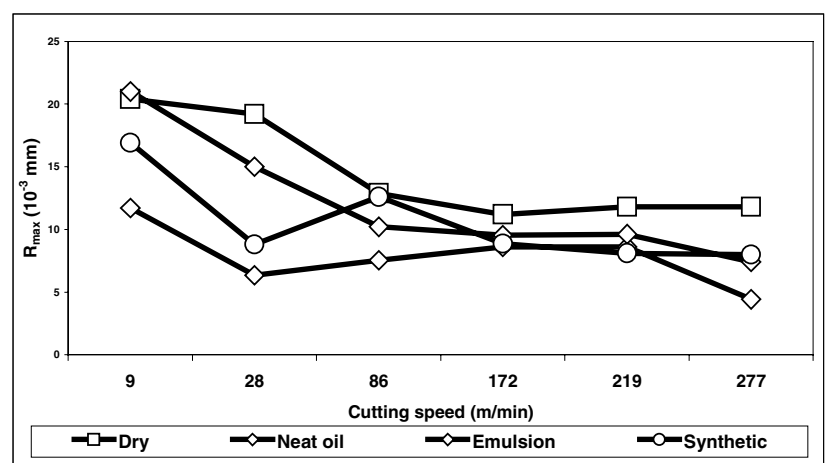

Figure 15. Maximum surface finish (Rmax) at various cutting speed and fluids.

The pendular scratch test conducted at an approach speed of about $246 \mathrm{~m} / \mathrm{min}$ and maximum scratch depths of $300 \mu \mathrm{m}$, succeeded in reproduction of the micro mechanisms actuating in the turning of steels. In addition, there is the fact that the indentersample interface temperature is high, although it was not measured. The specific energy levels and the chip colours can be used to judge the performance of the fluids. Therefore, this technique is a powerful laboratory tool for quick evaluation of the performance of cutting fluids for machining applications.

\section{Conclusions}

1. The methodology used for the linear scratch at constant load was not sufficient to explain the actuation of the fluid at the indenter-sample interface.

2. Pendular scratch is a dynamic test that allow classification of the cutting fluids using specific energy in the following order: neat oil, emulsion, dry, synthetic and water.

3. Pendular scratch reproduced the micro mechanisms actuating during turning, which makes it a powerful laboratory tool for the evaluation of cutting fluids.

4. Micro hardness of the chip increases in the following order: synthetic, emulsion, neat oil and dry.

5. The pendular scratch test show that both cooling and lubrication qualities are important for the classification of cutting fluids. Since the mass of material scratched is dependent on the lubricity and cooling properties of the fluid, a fluid with a high lubricity and a poor cooling ability would give lower specific energy value.

6. Machining under dry conditions generated the worst surface finish while the cutting fluids gave better surface finishes in all the speed range investigated.

\section{Acknowledgments}

The authors would like to thank the Villares Metals, Sandvik and Shell for the supplying the work material, cutting tools and the fluids, respectively. Thanks also to FAPEMIG (Fundação de Amparo a Pesquisa do Estado de Minas Gerais), CNPq (Conselho Nacional de Desenvolvimento Científico e Tecnológico) and CAPES (Coordenação de Aperfeiçoamento de Pessoal de Nível Superior - Project PDE 0333-04-2) for providing the necessary funds for the research to be carried out.

\section{References}

Abrahão, A., Neto, F.P.L. and De Mello, J.D.B, 1998, "Automation of the linear scratch tests" [In Portuguese], IV Seminário de Desgaste, Associação Brasileira de Metalurgia e Materiais, ABM, São Paulo, SP, Brazil.

Backer, W.R., Marshall, E.R. and Shaw, M.C., 1952, "The size effect in metal cutting", Transactions of ASME, Vol. 74, pp. 61-72.

Bryggman, V., Hogmark, S. and Vingsbo, O., 1985, "Mechanisms of gouging abrasive wear of steel investigated with the aid of pendulum single pass grooving”, Annals of Int. Conf. on Wear of Materials, Canada, pp. 324331 .

Cselle, T., 1997, "Hartstoffbohrer: Schon voll augereizt?", Gühring, Sigmaringen, Laiz.

Chiffre, L., 1977, "Mechanics of metal cutting and cutting fluid action", International Journal of Machine Tool Design and Research, Vol. 17, No. 4, pp. 225-234.

Chiffre, L., 1978, "Testing the overall performance of cutting fluids", Lubrication Engineering, Vol. 34, No. 5, pp. 244-251.

Chiffre, L., 1991, "Lubrication in cutting - critical review and experiments with restricted contact tools", ASLE Transactions, Vol. 24, No. 3, pp. 340-344.

Chiffre, L., 1984, "Frequency analysis of surfaces machined using different lubricants", ASLE Transactions, Vol. 27, No. 3, pp. 220-226.

Chiffre, L., 1998, 'Function of cutting fluids in machining", Lubrication Engineering, Vol. 44, 6, pp. 514-518. 
El-Khabeery, M.M., Salch, S.M. and Ramadan, M.R, 1991, "Some observations of surface integrity of deep drilling holes", Wear, Vol. 142, pp. 331-349.

Ferraresi, F., 1977, "Fundamentals of metals machining", [In Portuguese], Ed. Edgard Blücher Ltda, Vol 1, São Paulo, Brazil, 751 pgs.

Franco, S.D., 1989, "Abrasive wear contribution of the poliphasic materials", [In Portuguese], MSc Thesis, Federal University of Uberlândia, Uberlândia, MG, Brazil, 115p

Lamy, B., 1984, "Effect of brittleness index and sliding speed on the morphology of surface scratching in abrasive or erosive processes", Tribology International, Vol. 17, No. 1, pp. 35-38.

Liang, Y.N., Li, S.Z., Li, D.F. and Li, S, 1996, 'Some developments for single-pass pendulum scratching", Wear, Vol. 199, No. 1, pp. 66-73.

Machado, A.R. and Wallbank, J., 1997, 'The effect of extremely low lubricant volumes in machining", Wear, Vol. 210, pp. 76-82.
Raslan, A.A. 1991, "Linear scratch of brittle materials", [In Portuguese], Technical Report of the Pos-Doc., Proc. $\mathrm{N}^{0}$. 23.123.007.313/9018.

Sales, W.F., Guimarães, G, Machado Á.R. and E.O. Ezugwu, 2002, "Cooling ability of cutting fluids and measurement of the chip-tool interface temperatures", Industrial Lubrication and Tribology, Vol. 54, No. 2, pp. 5768.

Taylor, F.W., 1907, "On the art of cutting metals", Transactions of the American Society of Mechanical Engineers, New York, Vol. 28, pp. 31-58.

Trent, E.M., 1991, "Metal Cutting", $3{ }^{\text {rd }}$ Edition, Butteworths-Heinemann Ltd, 273 pg.

Wakabayashi, T. and Ogura, S., 1989, "Evaluation of cutting fluids by consumption energy in tapping test", J. of the Soc. of Tribologists and Lubrication Engineers, Vol. 46, 11, pp.716-720. 